\title{
Debatedor
}

\section{Saúde do Trabalhador e Modelo de De- senvolvimento: aprofundando as origens e as contradições dos entraves}

Worker's health and development model: plunging into the origins and contradictions of the hindrances

Marcelo Firpo Porto ${ }^{1}$

O convite para debater o artigo Saúde do TrabaIhador no SUS: desafios para uma política pública (COSTA; LACAZ; JAKSON FILHO; VILELA, 2013) suscitou, inicialmente, uma dúvida: teria eu condições de discutir questões atuais de saúde do trabalhador, uma vez que há vários anos venho priorizando minha área de atuação no campo da saúde e ambiente, em especial em torno da ecologia política e dos movimentos por justiça ambiental? Porém, considero ser esta uma oportunidade de diálogo para com o campo que atuei desde 1985, incluindo parcerias importantes com companheiros como Francisco Lacaz e Danilo Costa. Dessa forma, pretendo contribuir, dentro das limitações desse espaço, com um diálogo que, a partir dos referenciais e das experiências sobre a relação entre saúde, produção, ambiente e desenvolvimento, possa ampliar e estabelecer novas possibilidades de compreensão dos desafios atuais da saúde do trabalhador, que, como veremos, são também da própria Saúde Coletiva.

Pretendo, neste comentário, aprofundar o entendimento acerca das dificuldades apontadas ao longo do artigo para a implementação das políticas públicas em saúde do trabalhador, em que pesem os avanços decorrentes da publicação da Política Nacional de Segurança e de Saúde do Trabalhador pelo Ministério do Trabalho e Emprego, em 2011 (BRASIL, 2011) e principalmente da Política Nacional da Saúde do Trabalhador e da Trabalhadora pelo Ministério da Saúde, em 2012 (BRASIL, 2012).
Na visão dos autores, das quais em linhas gerais compartilho, as contradições residem no contexto de crescimento econômico brasileiro e seus determinantes macroestruturais, que vem ocorrendo em detrimento das políticas sociais, segundo argumento recorrente, por meio da continuidade de políticas neoliberais que impedem avanços em diversas políticas sociais. Contudo, é necessário aprofundar e atualizar o que isso significa no quadro econômico e político que vem sendo tecido, em especial desde a virada do século com a chegada ao poder do Partido dos Trabalhadores através da eleição do presidente Lula.

A tese que defendo é de que, de certa forma, o campo da Saúde do Trabalhador encontra-se no limite possível dos avanços políticos e conceituais historicamente já construídos dentro do atual modelo de desenvolvimento seguido pelo país em sua inserção econômica e geopolítica no comércio global. Avanços pontuais, ainda que importantes, poderão ocorrer na medida em que atendam ou não firam interesses estruturais ou conjunturais que conformam o modelo hegemônico. Por exemplo, ações de enfrentamento do trabalho escravo, questões de gênero, redução da informalidade, melhorias pontuais em regiões e atividades econômicas nas quais riscos e problemas de saúde tenham implicações políticas e econômicas relevantes, sendo enfrentados pelo SUS, Cerests minimamente organizados, com o apoio técnico-científico da academia e apoio político de movimentos de trabalhadores. Ou, ainda, quando conjunturas políticas favoráveis propiciem políticas mais ousadas em defesa dos trabalhadores, fato cada vez mais raro diante das coalizões políticas que limitam ações progressistas dos partidos de esquerda no poder. Aliás, avanços da Reforma Sanitária e do SUS como um todo sempre caminharam quando contaram com o apoio de forças progressistas (PAIM, 2008). Tais avanços, contudo, continuarão na atualidade a esbarrar na falta de apoio político e institucional em âmbitos federal, estadual e municipal sempre que ameaçarem os principais pilares das políticas de 
crescimento econômico. Nesse sentido, uma política integral e intersetorial de saúde do trabalhador está longe de ser uma prioridade do modelo.

Todavia, em que consiste este modelo hegemônico de crescimento típico do conjunto da América Latina, ainda que com distintos matizes de natureza econômica e ideológica, esta no sentido de uma maior ou menor ousadia redistributiva via políticas sociais como seguridade social, saúde e educação? A visão a seguir sintetiza, de forma bem pessoal, aprendizados provenientes da ecologia política (PORTO; MARTINEZ-ALIER, 2008), da vertente ecomarxista (O'CONNOR, 2001), assim como da Medicina Social (BREILH, 2008) e da Saúde Coletiva (RIGOTTO, 2011).

De forma bem sintética, o modelo de desenvolvimento econômico, também denominado extrativista e de pilhagem, está fortemente baseado na inserção no comércio internacional global via exportação de commodities agrícolas (grãos, carne, celulose...) e metálicas (ferro, ouro, prata, mas também metais brutos processados, como aço e alumínio, no caso brasileiro), além do petróleo. Tal concepção obsessiva de crescimento econômico, aliada ao aumento do consumo doméstico obtido pelo aumento da renda dos trabalhadores através de políticas redistributivas, incluindo políticas sociais focais como o bolsa família, tem propiciado um leque de alianças entre grupos nacionalistas, de esquerda e direita. Portanto, a inclusão social via inserção dos pobres na classe média é vista como estratégia para fortalecer o mercado doméstico, sendo tal discurso incorporado por diferentes setores políticos e econômicos, incluindo o setor financeiro e o agronegócio. A crise ambiental, quando reconhecida, é resolvida pelos instrumentos da ecoeficiência e da economia verde (PORTO; SCHÜTZ, 2012), visto que processos regulatórios que bloqueiam o crescimento econômico são considerados empecilhos ao progresso. Ecologistas fora desse esquema são vistos como fundamentalistas e inimigos da nação, como expresso na declaração do ex-presidente Lula: "o país não pode ficar a serviço de uma perereca..."”. Marcos legais ligados ao meio ambiente direta ou indiretamente (como o Código Florestal e o de Mineração) são revistos sob a pressão do agronegócio e de mineradoras, e o licenciamento ambiental é flexibilizado. Nesse contexto, indicadores econômicos e sociais positivos, lógicas de governabilidade e vitórias nas disputas eleitorais servem como justificativa pragmática e critérios de ação política e gestão pública.
Em recente trabalho (RODRIGUES, 2013), o Observatório Internacional de Capacidades Humanas, Desenvolvimento e Políticas Públicas da UNB analisa vários indicadores que parecem justificar a hegemonia desse modelo nos últimos anos, principalmente na América do Sul. Algumas características gerais: (1) a urbanização e a ocupação crescem, e o desemprego e a informalidade tendem a cair, com exceção do México que expressa a crise do modelo $\mathrm{Nafta}^{3}$; (2) melhoria absoluta no Índice de Desenvolvimento Humano (IDH) no conjunto da América Latina e dos BRICS ${ }^{4}$, sendo o destaque no Brasil para educação e saúde; (3) queda nos indicadores de pobreza e desigualdade de rendimentos, embora a desigualdade continue elevada face ao déficit histórico; (4) avanços educacionais indiscutíveis nas taxas de alfabetização, número médio de anos de estudo e frequência escolar; (5) queda nos diversos indicadores demográficos, como taxas de natalidade, mortalidade e fecundidade, implicando em baixo crescimento demográfico (faixa de 1\% a $1,5 \%$ a.a.). Aumento nos indicadores como proporção de idosos e expectativa de vida ao nascer, com menor pressão na previdência (caso haja emprego) nas próximas duas a três décadas em função do aumento proporcional da População Economicamente Ativa (PEA); (6) na saúde, acelera-se a transição epidemiológica, com aumento das crônico-degenerativas e causas externas. $\mathrm{O}$ gasto em saúde - público e privado - eleva-se no que diz respeito à proporção do Produto Interno Bruto (PIB) e também em termos per capita, com demanda crescente por ampliação do acesso e da qualidade.

Ainda com relação à saúde pública e levando em consideração as agendas recentes no Brasil, podemos apontar algumas características reforçadas pelo modelo hegemônico de desenvolvimento econômico, por exemplo: o mercado como instrumento de gestão e qualidade, com o "choque de gestão" para o SUS e o incremento da relação público-privado; saúde como motor do desenvolvimento, por exemplo, através do complexo industrial da saúde; com relação ao SUS, a preocupação central - legítima - é ampliar o acesso à rede assistencial e a procedimentos de saúde. O problema é que isso se realiza dentro de um reducionismo despolitizador da própria reforma sanitária, com políticas restritas de vigilância em saúde, ou ainda de uma promoção concebida no plano individual da qualidade de vida, abrindo-se mão de uma concepção ampla de vigilância da saúde e políticas intersetoriais. Pesquisas induzidas em

\footnotetext{
${ }^{2}$ Nota do editor: exemplo de divulgação do episódio pela imprensa: MERGEN, G. Lula diz que país não pode ficar a serviço de uma perereca. Portal Terra, 29 jul. 2010. Disponível em: <http://noticias.terra.com.br/brasil/lula-diz-que-pais-nao-pode-ficar-a-servico-de-uma-perereca,da3c6 3fc8940b310VgnCLD200000bbcceb0aRCRD.html>. Acesso em: 04 dez. 2013.

${ }^{3}$ North American Free Trade Agreement (Tratado Norte-Americano de Livre Comércio).

${ }^{4}$ Acrônimo para definir a associação das 5 maiores economias emergentes: Brasil, Rússia, Índia, China e África do Sul.
} 
saúde do trabalhador e ambiental reproduzem esse reducionismo ao se concentrarem em agravos específicos, situações de risco e medidas mitigadoras/ compensatórias, havendo uma enorme lacuna justamente no tema das políticas públicas intersetoriais e abrangentes em saúde do trabalhador.

É importante ressaltar que não apenas o Brasil, mas sim o conjunto da América do Sul tem tido um crescimento consistente do PIB e do superávit fiscal desde o ano 2000, basicamente graças ao que os economistas denominam "Efeito China", com a elevação da demanda por commodities envolvendo minerais, alimentos e energia e que sustentou a região mesmo na crise financeira de 2008. A China também é responsável pela queda do preço mundial de vários produtos industrializados, favorecendo a ampliação mundial do consumo de massa. Nesse quadro, uma nova conformação geopolítica parece estar se constituindo, ainda não muito clara, em que países com governos mais à esquerda da América Latina assumem a transformação social pela inserção nas regras do jogo do comércio internacional, trabalhando "por dentro".

Nesse momento, estão sendo formadas alianças estratégicas envolvendo interesses dos países emergentes, dos BRICS, dos antiamericanos, dentre outros, com uma estranha mescla de ideologias neoliberal, nacionalista e produtivista que pensa na virada do jogo ideológico pelo aumento do poderio geopolítico desses países. As alianças nacionais e internacionais formaram blocos políticos inimagináveis até algum tempo atrás: partidos de esquerda no poder junto com inúmeros outros partidos; economistas do Banco Mundial e dos Bancos Centrais de ideologia neoliberal; empresários, preferencialmente nacionais, mas não exclusivamente; setores econômicos como o agronegócio, a mineração, a infraestrutura e as indústrias específicas; e setores militares nacionalistas, como no Brasil na defesa de programas como o submarino nuclear. No Equador, por exemplo, ambientalistas foram presos há algum tempo por protestarem em frente da embaixada da China, e este mesmo país possui cooperação com a Rússia para iniciar a mineração de urânio com a promessa de transferência de tecnologia futuramente para reatores nucleares. Naturalmente isso é um poço de contradições que tendem a se aflorar, embora com certo afinamento discursivo de vários líderes políticos de Brasil, Argentina, Equador, Venezuela e Bolívia, dentre outros. Por exemplo, atacam os "fundamentalistas" indígenas, ambientalistas e ONGs como antiprogresso ou frutos de manipulações de interesses do centro imperialista.

Outra questão complexa e central para entendermos a expansão desse quadro no Brasil, e que o artigo apenas enuncia, é a posição pouco crítica e de adesão ao modelo de desenvolvimento presente em boa parte do movimento sindical. Algumas pistas são dadas no artigo, como o caráter fragmentado e corporativo do tripartismo assumido pelo Ministério do Trabalho e Emprego (MTE), problema reforçado com a chegada de vários quadros estratégicos do movimento sindical na saúde dos trabalhadores e que passaram a compor importantes escalões do governo federal. Uma consequência política desse processo diz respeito à perda de autonomia e combatividade do próprio movimento sindical, fato especialmente agravado por outro elemento indicado no artigo: o papel dos fundos de pensão de empresas estatais. Os três maiores do país (PREVI com R\$ 160 bilhões, PETROS com R $\$ 60$ bilhões e FUNCEF com R $\$ 50$ bilhões) desempenham um importante papel econômico e ideológico de atrelamento dos benefícios dos trabalhadores à lógica de mercado, visto que, em última instância, são os dividendos dos investimentos que importam, e não a construção de alternativas de desenvolvimento para o país. Esse é um importante mecanismo ideológico de despolitização que tem passado despercebido em diversas análises críticas sobre o atual modelo de desenvolvimento.

O quadro desenhado pelo artigo e pelos presentes comentários é complexo e não muito alentador. Configura-se também em uma espécie de crise tanto de horizontes, como das bases morais em diversas instâncias políticas e institucionais. Verificamos mais e mais o esgarçar de discursos e práticas de partidos e lideranças, inclusive com posições importantes no passado e no presente no campo da saúde do trabalhador e ambiental, e crescem os conflitos de interesse envolvendo questões éticas. Em nome da governabilidade, de alianças políticas, de disputas eleitorais e da defesa de projetos estratégicos de governo, surgem inúmeras contradições e limitações para avanços. No campo da saúde dos trabalhadores e ambiental, acrescentamos a lógica da mercantilização do próprio saber técnico-científico na manipulação de incertezas a serviço de interesses jurídicos ou de marketing das empresas, o que tem envolvido um número crescente de profissionais, inclusive de universidades públicas, como consultores ou coordenadores de pesquisas dirigidas. Os conflitos de interesse e dilemas éticos são por vezes camuflados através de estratégias como a política de "uma mão lava a outra”, ou seja, abraça-se uma causa pública que visa ocultar outras contradições. Enfim, a confusão política, institucional e moral é grande e não há perspectivas de ser reduzida.

Diante do exposto, que alternativas podem surgir para além de avanços pontuais possíveis, ainda que importantes, no atual quadro? Encerro os comentários com algumas breves sugestões na busca de alternativas e avanços. 
- A crise do modelo de desenvolvimento não afeta só o campo da saúde do trabalhador, e sim o conjunto da Saúde Coletiva brasileira e da Medicina Social Latino Americana. Considero estratégica uma aliança com o movimento da reforma sanitária e da saúde coletiva na compreensão crítica dos limites teóricos, na produção de alternativas e no enfrentamento dos mal-estares que estão presentes em todos que ainda lutam pelos princípios fundamentais do SUS. De certa forma, isso já vem acontecendo de muitas maneiras em iniciativas realizadas pelo Cebes e pela Abrasco, e a saúde do trabalhador é estratégica nesse movimento. Evoco aqui as sábias palavras de Gastão Wagner (CAMPOS, 2000) de que a saúde coletiva implica na defesa da vida e da democracia, e deve trabalhar com autonomia relativa tanto em relação ao Estado, quanto a partidos políticos, ideologias e outras racionalidades técnicas. Neste momento, é estratégico ampliar nossa autonomia para que uma reflexão crítica e inspiradora ilumine novos caminhos em torno de futuros projetos de sociedade.

- Outra questão central é a ampliação de conceitos como trabalho, saúde e desenvolvimento. No campo da saúde do trabalhador, uma importante contribuição já vem sendo realizada por áreas inovadoras, como a ergologia, que discutem questões como gênero e coletivos de trabalho. Porém, é necessário avançar em direção à compreensão de outras alternativas de desenvolvimento e economia. Importantes pistas vêm sendo dadas por abordagens territoriais e das discussões sobre os conflitos ambientais, que trazem à tona simultaneamente temas como sustentabilidade e os direitos humanos fundamentais. Indígenas, camponeses, pescadores, quilombolas, movimentos culturais das periferias urbanas, movimentos pela democratização e humanização das cidades, experiências da reforma agrária e de agroecologia, de luta contra o racismo institucional e ambiental, tudo está ocorrendo neste momento e incluem trabalhadores envolvidos em áreas e discussões frequentemente desconsideradas pelas discussões do campo. As discussões sobre conflitos ambientais revelam a concretude do modelo, do comércio internacional injusto e de seus impactos sobre inúmeras populações e ecossistemas, envolvendo a expansão do agronegócio, da mineração, dos portos de exportação e da exploração de fontes energéticas, como petróleo, hidrelétricas, agrocombustíveis, nuclear a até mesmo a eólica, já que diversos parques têm afetado camponeses, quilombolas e indígenas no nordeste.

- Para seguir o item anterior, é necessário revitalizar teoricamente alternativas de compreensão e produção de saberes sobre problemas e alternativas. Por exemplo, existe uma densa produção crítica latino-americana que ainda circula pouco no âmbito da saúde coletiva, e menos ainda na saúde do trabalhador. Refiro-me aos chamados estudos subalternos ou teorias descoloniais de autores como Aníbal Quijano, Ramón Grosfoguel, Walter Mignolo, Enrique Dussel e, de certa forma, também as contribuições mais conhecidas de Boaventura de Sousa Santos. Eles buscam desconstruir a noção do proletariado como sujeito histórico central dos processos de transformação social. Tais contribuições compreendem que os processos emancipatórios deveriam forçosamente articular as lutas das classes trabalhadoras com as de todos os outros grupos dominados e oprimidos no sistema-mundo, os quais foram desprezados como "sujeitos não históricos" pelo marxismo eurocêntrico. No nosso caso, isso traz à tona discussões como o racismo histórico que discrimina saberes, modos de vida e cosmologias de povos indígenas, além dos quilombolas, campesinos e pescadores. Trata-se de uma discussão não só política, mas também e essencialmente epistemológica, já que as formas de produção de conhecimento hegemônicas legitimam e tornam sutilmente obscuras as categorias e as relações que reproduzem formas de poder que se encontram por detrás dos processos de inferiorização, exclusão, dominação e exploração. É por isso que diversos autores, como Boaventura Santos, dão centralidade aos processos transculturais através de encontros, diálogos ou ecologia de saberes.

As contribuições discutidas no último tópico são consistentes com o que autores ecomarxistas apontam como a segunda grande contradição do sistema capitalista contemporâneo, associada às condições de produção e que incluem as problemáticas ambientais, de gênero, e étnicas dentre outras. Seus principais protagonistas são coletivos contra-hegemônicos, como feministas, ambientalistas, povos tradicionais, agricultores familiares ligados à agroecologia, organizações de justiça ambiental, dentre outros. Elas estão presentes, por exemplo, no Encontro Diálogos e Convergências entre Movimentos Sociais, e que gerou uma bela Carta Política ${ }^{5}$. Experiências atuais de vanguarda vêm se constituindo como exemplos de diálogos de saberes entre movimentos sociais e grupos acadêmicos, como as

${ }^{5}$ Ver a Carta Política em: http://dialogoseconvergencias.org/noticias/carta-politica-do-encontro-nacional-de-dialogos-e-convergencias. 
ações de vigilância popular da saúde realizadas por Raquel Rigotto e o grupo Tramas da Universidade Federal do Ceará; ou o Observatório da Política Nacional de Saúde Integral das Populações do Campo e da Floresta, coordenado por Fernando Carneiro da UNB. Certamente há um enorme percurso a ser trilhado para que processos legítimos, porém atomi-

\section{Referências}

BRASIL. Decreto nº 7.602/2011, de 07 de novembro de 2011. Dispõe sobre a Política Nacional de Segurança e Saúde no Trabalho. Diário Oficial [da] República Federativa do Brasil, 08 nov. 2011. Disponível em: <https://www.planalto.gov.br/ccivil_03/ ato20112014/2011/decreto/d7602.htm>. Acésso em: $5 \mathrm{dez}$. 2013.

. Ministério da Saúde. Portaria n⿳ำ 1.823, de 23 de agosto de 2012. Institui a Política Nacional de Saúde do Trabalhador e da Trabalhadora. Diário Oficial [da] República Federativa do Brasil, nº 165, Seção I, p. 46-51, 24 ago. 2012. Disponível em: <http://bvsms.saude.gov.br/bvs/saudelegis/gm/2012/ prt1823_23_08_2012.html>. Acesso em: 5 dez. 2013.

BREILH, J. Pilhagens, ecossistemas e saúde. In: MIRANDA, A. C. et al. Território, Ambiente e Saúde. Rio de Janeiro: Fiocruz, 2008. p. 159-180.

CAMPOS, G. W. S. Saúde pública e saúde coletiva: campo e núcleo de saberes e práticas. Ciência \& Saúde Coletiva, Rio de Janeiro, v. 5, n. 2, p. 219-230, 2000.

COSTA, D.; LACAZ, F. A. C.; JAKSON FILHO, J. M.; VILELA, R. A. G. Saúde do Trabalhador no SUS: desafios para uma política pública. Revista Brasileira de Saúde Ocupacional, São Paulo, v. 38, n. 127, p. 11-30, 2013. zados, possam ir se articulando e construindo alternativas políticas mais consistentes. Porém, a crítica à fragmentação e ao receio de pós-modernismos relativistas pode recair na defesa de dogmas ainda muito fortes e que acabam por impedir a necessária renovação intelectual e espiritual da saúde coletiva e de todas as áreas que militamos.

O'CONNOR, J. Causas naturales: ensayos de marxismo ecológico. México: Siglo XXI, 2001.

PAIM, J. S. Reforma sanitária brasileira: avanços, limites e perspectivas. In: MATTA, G. C.; LIMA, F. C. J. (Org.). Estado, sociedade e formação profissional em saúde: contradições e desafios em 20 anos de SUS. Rio de Janeiro: Fiocruz/EPSJV, 2008.

PORTO, M. F; MARTINEZ-ALIER, J. Ecologia política, economia ecológica e saúde coletiva: interfaces para a sustentabilidade do desenvolvimento e para a promoção da saúde. Cadernos de Saúde Pública, Rio de Janeiro, v. 23, suppl. 4, p. S503-S512, 2007.

PORTO, M. F.; SCHUTZ, G. E. Gestão ambiental e democracia: análise crítica, cenários e desafios. Ciência \& Saúde Coletiva, Rio de janeiro, v. 17, n. 6, p. 1447-1456, 2012.

RIGOTTO, R. M. Os conflitos entre o agronegócio e os direitos das populações: o papel do campo científico. Revista Pegada Online, Presidente Prudente, v. 12, n. 1, 123-140, 2011. Disponível em: <http://revista. fct.unesp.br/index.php/pegada/article/view/918/947>. Acesso em: 4 dez. 2013.

RODRIGUES, V. A. (org). Observatório Internacional de Capacidades Humanas, Desenvolvimento e Políticas Públicas: estudos e análises n. 1. Brasília: NESP/UNB, 2013.

Recebido: 17/09/2013

Aprovado: 27/09/2013 